\title{
Using the exploration of a story to consider the meaning of becoming older
}

\section{Kirsten Jack}

Manchester Metropolitan University, UK

\begin{abstract}
The aim of this study was to explore the use of a creative teaching method to facilitate learning about becoming older. An excerpt from a story was shared with a group of first year undergraduate student nurses. This was followed by a discussion of the holistic aspects of ageing. Use of this method encouraged a more critical discussion of ageing when compared to didactic teaching methods, and this approach is not restricted to nursing practice. This method can guide similar work in any subject in which assumptions can be challenged, and where meaningful discourse needs to be encouraged.
\end{abstract}

Keywords: education; creativity; literature; nurse; older people.

\section{Introduction}

This study explores the use of a story excerpt to support learning about what it means to become older. It is important to consider meaningful ways to learn about what it feels like and means to become old. In the United Kingdom (UK), over 14 million people are aged sixty and above (ONS, 2011). Nearly two thirds of hospital admissions involve the over 65 year old age group (Cornwell et al., 2012), and as a group older adults are the main users of health services. However, the needs of the older person are not always met. Reports from the Care Quality Commission (2011), a UK body responsible for the checking and monitoring of hospitals, suggest that there are inadequacies in care provision, in areas such as interpersonal communication and the respect of dignity. Nurse lecturers are challenged to consider effective ways to facilitate effective learning about this area of practice. 


\section{Background}

In the developed world, the chronological age of sixty five years has been accepted as a definition of an older person (WHO, 2013) although for many, age is merely a state of mind and considering the individuality of older people is key to genuine care (Davies, 2011). However, whilst the ethos of individualised care may be encouraged within the higher education setting, it may not be the reality in practice (Alabaster, 2007). Student nurses might be faced with emotional incongruence, making their work with the older person less meaningful, and the reality of nursing practice might be very different to their vision on entering the profession.

Reflective practice is a way for nurses to reflect on their professional development (Rolfe et al., 2011). It might support the development of critical thinking skills, help reduce the theory/practice gap (Burton, 2000), and change future practice in a positive way (Bulman, 2008). Reflective practice has been used to learn from experiences relating to communication, ethics and confidentiality (Keen, 2000) and is an educational and professional requirement for nurses (NMC, 2008). It is a way to 'disperse the emotional load' created when caring for others (Rees, 2013, p.51), and assists in the understanding of ourselves (Johns, 2009). This form of experiential learning is not restricted to health care students and has been used in the training of other professionals, such as legal and education (Le Brun et al., 2005; Hume, 2009). However, its overuse as a learning method has been suggested, with nurses showing signs of suffering 'reflection fatigue' (Coward, 2011, p.883). There are concerns about the ways in which the concept is defined and has been communicated to others (Glaze, 2001). Self-reflection might be stifled particularly if reflective accounts are assessed as part of the undergraduate curriculum outcomes. Less 'formal' ways to reflect, such as sharing feelings through collage (Jack, 2012), and story sharing (Coward, 2011), can support deeper levels of learning about practice, and there is growing interest among nurse educators to consider creative ways to reflect and learn about practice.

\section{Creativity in teaching}

Fleming et al. (2011) suggest that student nurses do not use a dominant learning style and advocate use of a range of teaching and learning methods to maximise learning potential. When exploring emotions and self-development, traditional didactic teaching methods can 
fall short. Freshwater and Stickley (2004) advocate a transformatory learning process, which includes reflective learning and use of the arts, such as poetry, drama, music and film. Story extracts can be used to explore understanding of what it is to be human, as part of the education of health professionals (Gallagher and McKie, 2010), and can assist not only in our understanding of others, but also of ourselves (Price et al., 2007). Creative learning methods support a deeper level of learning (Ramsden, 1992) and creativity in teaching can support the development of analytical and problem solving skills (Sternberg, 2008). Literature, such as stories, can enhance 'moral sensitivity' in the novice learner (Begley, 2006, p.264) and can encourage the reader to become involved in the experience rather than feel like they are watching from the side-lines. Stories encourage students to explore personal issues and can support a sense making process in relation to their own lives (Koenig and Zorn, 2002). Crawley et al. (2012, p.45) describe books as a 'rich resource' for educators when encouraging the development of emotional awareness, for example, when exploring issues such as death and dying. Stories are processed more fully than other stimuli (Newman, 2003) and provide a way for students to rehearse reactions and feelings about sensitive topics in a safe environment, before being exposed to the reality of the clinical area (Hargrave, 1985).

\section{Challenges}

In common with other teaching methods, the use of stories in the classroom is not without its challenges. The fact that this method can support deeper levels of reflection and thinking, on the one hand beneficial, can lead to challenging classroom situations which might be difficult for educators to manage. The multiple meanings located within stories can lead to an unpredictable learning environment which not only challenges students theoretically but also emotionally and in relation to their sense of self. Gallagher and McKie (2010) suggest that educators need to be patient and sensitive to the needs of students whilst at the same time, remaining prepared for the unexpected. They suggest that educators adopt a friendly and informal approach to the process and explore reading sources which appeal to a range of students' reading habits. However, when exploring emotions through the arts, care must be paid, not only to the students' wellbeing, but to ways in which educators can be supported to facilitate such learning (Freshwater and Stickley, 2004). Lillyman et al. (2011) suggest that all student centred teaching methods require careful planning and skilled facilitation, as educators need to incorporate their 
pastoral role into their formal teaching. Ultimately, educators might find creative teaching methods too draining if not adequately supported themselves.

\section{Methodology}

At the beginning of the class the aims of the teaching approach were discussed with a group of ten first year student nurses. I read aloud the following excerpt from The Classic Tale of the Velveteen Rabbit (Williams, 1922/1991) and then asked the students to read it again and write down their related thoughts and feelings.

The story involves two nursery toys, a Velveteen Rabbit and a Skin Horse. The Skin Horse is the oldest toy in the nursery and the Rabbit perceives that he is wise and has experience. To the Rabbit, this makes him a reliable toy to answer questions about what it takes to become 'Real':

"What is REAL?" asked the Rabbit one day, when they were lying side by side near the nursery fender, Before Nana came to tidy the room. "Does it mean having things that buzz inside you and a stick-out handle?"

"Real isn't how you are made", said the Skin Horse. "It's a thing that happens to you. When a child loves you for a long, long time, not just to play with, but REALLY loves you, then you become Real."

"Does it hurt?" asked the Rabbit.

"Sometimes," said the Skin Horse, for he was always truthful. "When you are Real you don't mind being hurt."

"Does it happen all at once, like being wound up," he asked, "or bit by bit?" "It doesn't happen all at once," said the Skin Horse. "You become. It takes a long time. That's why it doesn't often happen to people who break easily, or have sharp edges, or who have to be carefully kept. Generally, by the time you are Real, most of your hair has been loved off, and your eyes drop out and you get loose in the joints and very shabby. But these things don't matter at all, because once you are Real you can't be ugly, except to people who don't understand." (Williams, 1922/1991, p.10 - 11) 
I used McDrury and Alterio's (2002) model to encourage reflective thinking about the meaning of becoming older. Their 'Reflective Learning through Storytelling' process includes five stages; finding, telling, expanding, processing and reconstructing.

\section{Story finding}

Crawley et al. (2012) suggest that educators need to find a book to which they have an emotional response and which relates to the nursing curriculum. I chose this excerpt for two reasons. First, my interpretation, as facilitator of the class, was that it encourages a shift away from a focus on the physical to the emotional aspects of care. Second, I suggest that there are multiple meanings within it and I hoped that it might encourage a wide-ranging discussion. However, I acknowledge that although the excerpt had emotional and theoretical significance for me, it may not appeal to the students. Some students might not even consider the piece to relate to ageing at all. The nature of interpretation means that each individual may view the world in a different way. However, this difference is advantageous and can promote discussion, disclosure and analytical skills within a group. At the start of the class I briefly disclosed my own feelings in relation to the piece, although I wanted the participants to discover their own meanings within it.

\section{Story telling}

I consider myself a novice in using children's stories in my teaching. I lacked confidence in reading out the whole story to the students and did not want to take up too much time, being concerned that I might lose the attention of some of the group. I read the excerpt aloud to the students, using the original book so that they could see the pictures which accompanied the text. I also distributed typed copies of the excerpt and gave the students time to re-read the piece at their own pace. I requested that the students documented their thoughts and feelings on paper, to support their contribution to the discussion and add to my evaluation of the exercise. I planned a break following the reading of the excerpt, so the students could buy drinks and have further time before starting the discussion. This gave the students an additional opportunity to consider and reflect on the piece. 


\section{Story expanding}

The student nurses involved in this study were unfamiliar with this style of teaching. They were eight months into a three year programme and, due to their early stage, much of the teaching they had been exposed to was didactic and theory based. The BSc (Hons) Adult Nursing curriculum becomes more enquiry based during years two and three. Therefore I expected that some of the students might struggle with the exercise and be unable to explore and reflect on possible meanings. Story expanding requires the students to explore beliefs and assumptions whilst reflecting on the various meanings within the story. Some students described how the excerpt had encouraged them to reflect on their own values in relation to older people, and had reinforced the need to respect the older person. All of the students contributed to the discussion, and the overwhelming theme related to the value, or lack thereof, of the older person. Anonymous identifiers are used during a thematic data presentation:

\section{Theme one: value of older people}

One student said:

Age shouldn't matter really, although it does, but you are still a person, and you get more valuable as you get older. (Jill)

Another stated:

Experiences make people valuable; it's not just about being young and fit. (Sue)

Some students considered the learning gained through engagement with the older person, and acknowledged that the worth of the older person is related to their physical functioning. The older person was viewed as knowledgeable and instrumental in giving us the life we lead today. One student made direct reference to the excerpt:

"...you can't be ugly, except to people who don't understand"; it's like people who lack respect for those older and wiser. The elderly of today fought in wars...they helped build the economy...they fought for our freedom. They died to give us what we have. What does it cost us to have a bit of respect and patience in return? (Fiona) 


\section{Theme two: needing to look 'beyond the physical'}

The second major theme for discussion was about the need to look beyond the 'physical' when treating patients, and to consider their emotional needs. This was particularly pleasing as when using traditional teaching approaches, my experience was that students tended to focus on the physical needs and a medical approach to care. Indeed Williams (2013) suggests that in comparison to the physical aspects of care delivery, the emotional nature of nursing has received little attention and a task-orientated approach to care prevails. One student said:

People who are old look tired due to how they have lived, but they are still a person and should be treated like one. (Debra)

Positive aspects of ageing emerged, such as the issue of developing experience as people become older:

Looking older shows life's experience, it shouldn't be seen as a bad thing. (Sue)

\section{Theme three: emotional needs}

Emotional need was highlighted as something that was still important to the older person:

Older people still have feelings and still want to be loved, just as much as younger people, but this can be ignored I think, especially when they get ill. (Carol)

The potential for conflict within families was something to consider:

Older people suffer emotional pain like loss, grief, arguments and fallouts or harsh words with families. (Fiona)

\section{Story processing}

My move away from a didactic to a more exploratory teaching style was in an attempt to encourage more meaningful and deeper levels of learning and discussion in the classroom. Novice reflectors often describe events, drawing conclusions often in an 
unconscious manner and without knowing whether the conclusions are appropriate (Williams, 2000). Group reflection on practice, facilitated in this case through use of the story excerpt, provides the space needed for thinking which enables deeper levels of reflection (Regan, 2008). Through the processing stage, the students were able to unpack feelings about their own mortality and their values and beliefs about how it feels to become older. We related our reflection to communication theory, particularly the work of Rogers (1961), and explored issues such as empathising with others and the importance of remaining self-aware.

The excerpt relies heavily on metaphorical language, which can deepen our understanding of the human condition (Foster and Freeman, 2008). Barker (2000, p.98) describes its use:

The careful and, in some cases, clever use of language can help us to get close to experiences, by approaching them indirectly. We can lose ourselves in an experience, when metaphor - whether verbal or visual - helps us 'see' something for what it really is, by using a phrase or image which clearly belongs to something else...

In this exercise, metaphor was a powerful medium to uncover hidden aspects of what it means to become older and encouraged a holistic discussion of ageing. It encouraged empathy for the older person, as the participants related the metaphors to their own experiences and assertions. Metaphor engages the reader, as they are required to think about the multiple meanings within a text, in contrast to literal information, which may at times require little thought, or mindful investigation. Paradoxically, we may only consider the reality of the issue as we investigate the 'unreal', and move away from factual informative text.

\section{Story reconstructing}

Use of the excerpt provided an effective way to promote critical reflection and thinking about what it means to get older. It was a helpful way to explore students' personal and practical experiences and provided a way to discuss some communication theory. The aim of story reconstructing is to support students in exploring how their practice might change and although this might be difficult to measure, written comments from the students in the 
classroom suggested that the experience was educationally valuable and encouraged thinking about practice:

This does have some meaning about how people perceive other people. (Sue)

This is like seeing the world through a child's eyes, which is good sometimes. (Debra)

\section{Implications}

I found that the use of this method supported an exploration of the human aspects of nursing and encouraged a holistic discussion about the meaning of becoming older. Previously, this teaching session had adopted a didactic and theory driven approach, using electronic slides to convey the information and encourage discussion. However, a focus on the theory might neglect other aspects of professional development. To broaden professional thinking, teaching needs to move beyond only delivering theoretical principles (Begley, 2006) and be open to more creative methods of working. Openness to others' perspectives, found through the arts, enriches the imagination and context for understanding ourselves and others.

Being open to the uniqueness of another person is important in nursing practice. The older person has wide ranging needs which often go unmet when 'current acute models of care' are applied (Flatley and Bridges, 2008, p.333) and use of the excerpt encouraged open and honest discussion about the requirement to consider holistic needs. This is important, as admission to hospital can result in stereotyping and objectification of the older person, and a threat to their identity (Coyle, 1999).

This method can be replicated using other works and other contexts. I suggest that it is not restricted to teaching and learning about the older person and this philosophy can guide similar work in any subject in which assumptions can be challenged and discourse developed. The method could be developed by encouraging students to bring their own choice of literature to learning groups, although this might encourage a more unpredictable discussion, which may be more difficult for the lecturer to facilitate. This process may become lengthy and the approach itself might be perceived as increasing educator 
workload (Cho and Forde, 2001). However, to broaden professional thinking, teaching needs to move beyond only the delivery of theoretical principles (Begley, 2006).

\section{Conclusion}

Use of this method evaluated positively and exploration of the excerpt enriched discussion about what it is like to become older. The students were engaged with the discussion which was more analytical and autonomous when compared to previous methods of teaching in this subject area.

\section{References}

Alabaster, E. (2007) 'Involving students in the challenges of caring for older people', Nursing Older People, 19(6), pp. 23-28.

Barker, P. (2000) 'Working with the metaphor of life and death', Medical Humanities, 26(2), pp. 97-102.

Begley, A.M. (2006) 'Facilitating the development of moral insight in practice: teaching ethics and teaching virtue', Nursing Philosophy, 7(4), pp. 257-265.

Bulman, C. (2008) 'An introduction to reflection', in Bulman, C. and Schutz, S (eds.) Reflective practice in nursing. $4^{\text {th }}$ edn. Oxford: Blackwell science, pp. 1-24.

Burton, A.J. (2000) Reflection: nursing's practice and education panacea? Journal of Advanced Nursing 31 (5), pp. 1009 - 1017

Care Quality Commission (2011) Dignity and nutrition inspection programme: national overview. Newcastle: CQC.

Cho, M. and Forde, E. (2001) 'Designing teaching and assessment methods for diverse student populations International', Journal of Art and Design Education, 20(1), pp. 86-90. 
Cornwell, J., Levenson, R., Sonola, L. and Poteliakhoff, E. (2012) Continuity of care for older hospital patients: a call for action. London: Kings Fund.

Coward, M. (2011) 'Does the use of reflective models restrict critical thinking and therefore learning in nurse education? What have we done?', Nurse Education Today, 31(8), pp. 883-886.

Coyle, J. (1999) 'Exploring the meaning of dissatisfaction with health care: the importance of personal identity threat', Sociology of Health and IIIness, 21(1), pp. 95-123.

Crawley, J., Ditzel, L., and Walton, S. (2012) ‘Using children's picture books for reflective learning in nurse education', Contemporary Nurse, 42(1), pp. 45-52.

Davies, N. (2011) 'Reducing inequalities in healthcare provision for older adults', Nursing Standard, 25(41), pp. 49-55.

Flatley, M. and Bridges, J. (2008) 'Promoting the art of caring for older people (Editorial Debate)', International Journal of Nursing Studies, 45(3), pp. 333-334.

Fleming, S., Mckee, G. and Huntley-Moore, S. (2011) 'Undergraduate nursing students learning styles: a longitudinal study', Nurse Education Today, 31(5), pp.444-449.

Foster, W. and Freeman, E. (2008) 'Poetry in general practice education: perceptions of learners', Family Practice, 25(4), pp. 294-303.

Freshwater, D. and Stickley, T. (2004) 'The heart of the art: emotional intelligence in nurse education', Nursing Inquiry, 11(2), pp. 91-98.

Gallagher, A. and McKie, A. (2010) 'The potential of literature and poetry', in Warne, T. and McAndrew, S. (eds.) Creative approaches to health and social care education. London: Palgrave Macmillan, pp. 113-128.

Glaze, J. (2001) 'Reflection as a transforming process: student advanced nurse practitioners' experiences on developing reflective skills as part of an MSc programme', Journal of Advanced Nursing, 34(5), pp. 639-647. 
Hargrave, M.P. (1985) 'New horizons: literary studies in the nursing classroom', The Australian Journal of Advanced Nursing, 3(1), pp. 39-44.

Hume, A. (2009) 'Promoting higher levels of reflective writing in student journals', Higher Education Research and Development, 28(3), pp. 247-260.

Jack, K. (2012) “Putting the words "I am sad”, just doesn't quite cut it sometimes!': the use of art to promote emotional awareness in nursing students', Nurse Education Today, 32(7), pp. 811-817.

Johns, C. (2009) Becoming a reflective practitioner. $3^{\text {rd }}$ edn. Oxford: Blackwell Publishing.

Keen, A. (2000) 'Critical incident: reflection on the process of terminal weaning', British Journal of Nursing, 9(16), pp. 1059-1062.

Koenig, J.M. and Zorn, C.R. (2002) 'Using story telling as an approach to teaching and learning with diverse students', Journal of Nursing Education, 41(9), pp. 393-399.

Le Brun, M., Macduff, A., Vockovic, R. and Catanzariti, D. (2005) 'Developing the reflective practitioner online', The Law Teacher, 39(1), pp. 16-28.

Lillyman, S., Gutteridge, R. and Berridge, P. (2011) 'Using a storyboarding technique in the classroom to address end of life experiences in practice and engage students in deeper reflection', Nurse Education in Practice, 11(3), pp. 179-185.

McDrury, J. and Alterio, M. (2002) Learning through storytelling: using reflection and experience in a higher education context. New Zealand: Dunmore Press.

Newman, T.B. (2003) 'The power of stories over statistics', British Medical Journal, 327, pp. 1424-1427.

Nursing and Midwifery Council (2008) The code: standards of conduct, performance and ethics for nurses and midwives. London: NMC.

Office for National Statistics (2011) Mid 2010 population estimates. London: ONS. 
Price, S., Arbuthnot, E., Benoit, R., Landry, D., Landry, M. and Butler L. (2007) 'The art of nursing: communication and self-expression', Nursing Science Quarterly, 20(2), p. 155-160.

Ramsden, P. (1992) Learning to teaching in higher education. London: Routledge.

Rees, K.L. (2013) 'The role of reflective practices in enabling final year nursing students to respond to the distressing emotional challenges of nursing work', Nurse Education in Practice, 13(1), pp. 48-52.

Regan, P. (2008) 'Reflective practice: how far, how deep?', Reflective Practice, 9(2), pp. 219-229.

Rogers, C.R. (1961) On becoming a person. London: Constable.

Rolfe, G., Jasper, M. and Freshwater, D. (2011) Critical reflection in practice. $2^{\text {nd }}$ edn. Houndmills: Palgrave Macmillan.

Sternberg, R. (2008) 'Applying psychological theories to educational practice', American Educational Research Journal, 45(1), pp. 150-165.

Williams M (1922/1991) The Classic Tale of the Velveteen Rabbit or, How Toys Become Real. Ontario Running Press.

Williams, B. (2000) 'Collage work as a medium for guided reflection in the clinical supervision relationship', Nurse Education Today, 20(4), pp. 273-278.

Williams, A. (2013). 'Hochschild (2003) - The managed heart: the recognition of emotional labour in public service work', Nurse Education Today, 33(1), pp. 5-7.

World Health Organisation (2013) Definition of an older or elderly person. Available at: www.who.int/healthinfo/survey/ageingdefnolder/en/ (Accessed: $10^{\text {th }}$ July 2013). 


\section{Author details}

Kirsten Jack is a Senior Lecturer in the Department of Nursing, Manchester Metropolitan University. Her current research interests include the use of creative teaching methodologies to support self-awareness development among student nurses. She has recently launched a website www.caringwords.mmu.ac.uk which aims to encourage health care students to use poetry as a way to reflect on their practice. 